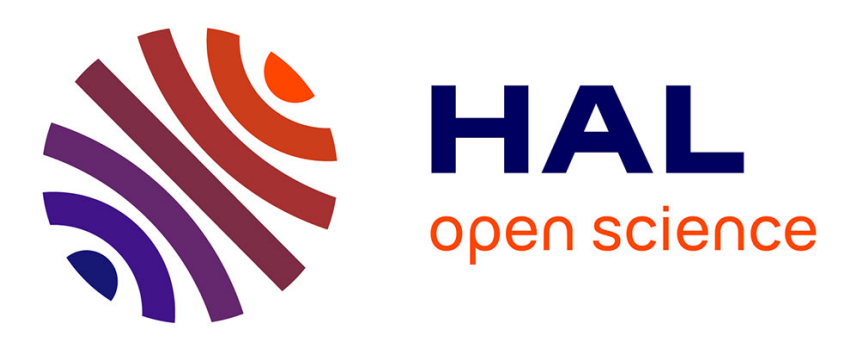

\title{
Crystalline thiophene - Calorimetric evidence for a glassy crystalline state in both phase sequences
}

P. Figuière, H. Szwarc, M. Oguni, H. Suga

\section{To cite this version:}

P. Figuière, H. Szwarc, M. Oguni, H. Suga. Crystalline thiophene - Calorimetric evidence for a glassy crystalline state in both phase sequences. Journal de Physique Lettres, 1984, 45 (24), pp.1167-1173. 10.1051/jphyslet:0198400450240116700 . jpa-00232465

\section{HAL Id: jpa-00232465 https://hal.science/jpa-00232465}

Submitted on 1 Jan 1984

HAL is a multi-disciplinary open access archive for the deposit and dissemination of scientific research documents, whether they are published or not. The documents may come from teaching and research institutions in France or abroad, or from public or private research centers.
L'archive ouverte pluridisciplinaire HAL, est destinée au dépôt et à la diffusion de documents scientifiques de niveau recherche, publiés ou non, émanant des établissements d'enseignement et de recherche français ou étrangers, des laboratoires publics ou privés. 
Classification

Physics Abstracts

$31.70 \mathrm{~K}-65.40-81.20 \mathrm{P}$

\title{
Crystalline thiophene - Calorimetric evidence for a glassy crystalline state in both phase sequences $\left({ }^{*}\right)$
}

\author{
P. Figuière, H. Szwarc \\ Laboratoire de Chimie-Physique des Matériaux Amorphes (**), \\ Université de Paris-Sud, 91405 Orsay Cedex, France \\ M. Oguni and H. Suga \\ Department of Chemistry and Chemical Thermodynamics Laboratory, \\ Faculty of Science, Osaka University, Toyonaka, Osaka 560, Japan
}

(Reçu le 29 juin 1984, accepté le 24 octobre 1984)

\begin{abstract}
Résumé. - Les deux séquences de phases du thiophène cristallin ont été étudiées au cours d'une nouvelle étude calorimétrique de ce composé, de 14 à $300 \mathrm{~K}$. On donne ici les températures de transitions de phase. Aux alentours de $40 \mathrm{~K}$, chacune des deux séquences de phases présente une transition vitreuse qui pourrait être liée au gel des réorientations moléculaires lors du processus d'ordonnancement à très basse température. Les grandeurs cinétiques qui caractérisent les relaxations enthalpiques dans chacune des deux phases cristal vitreux ont été déterminées : on obtient ainsi des enthalpies d'activation pour la relaxation voisines de celles qui régissent les mouvements de réorientation des molécules de thiophène autour d'un axe perpendiculaire au plan moléculaire dans les deux séquences de phases. Cela vient à l'appui de l'hypothèse selon laquelle relaxation enthalpique et réorientations moléculaires sont liées. Le rôle éventuel de la symétrie pseudo-pentagonale de la molécule de thiophène est évoqué.
\end{abstract}

\begin{abstract}
Both phase sequences of crystalline thiophene have been investigated during a new calorimetric study from 14 to $300 \mathrm{~K}$. The phase transition temperatures are reported. Around $40 \mathrm{~K}$, each phase sequence exhibits a glass transition which seems to arise from the freezing of the reorientational motion of the molecules at the low temperature stage of the ordering process. Kinetic data that characterize the enthalpy relaxation in both glassy crystalline states have been determined : this leads to activation enthalpies which are close to those associated with the in-plane reorientational motions of thiophene molecules in the corresponding phase sequences. This supports the hypothesis that both processes are related. Some speculations are made about the influence of the molecular quasi-five-fold symmetry.
\end{abstract}

In a recent work on solid thiophene [1, 2], calorimetric measurements performed between 77 and $250 \mathrm{~K}$ proved the existence of a stable crystalline phase (hereafter called phase II) that

(*) Contribution no 72 from Chemical Thermodynamics Laboratory. A preliminary account on this work was given at the Japan Calorimetry Conference which was held at Sendai in October 1982.

(**) Membre du LA 75, associé au CNRS. 
had remained unnoticed in a previous study made by Waddington et al. [3]. It also disclosed that transition II $\rightarrow$ III can easily be avoided during cooling, which leads to metastable phases with their own phase transitions. (See table I which gives the transition temperatures we determined in the present work.) The existence of metastable phases in thiophene was known before $[4,5]$ but these findings provided an explanation of previous confusing observations : this has been dealt within a former work [6], in which tentative rules were proposed to number metastable phases relative to stable ones (these rules will be used throughout the present work).

Many points remained to be cleared up : the calorimetric study referred to above [2] was performed on somewhat impure thiophene $(97.9$ or 98.9 mole $\%$ purity, depending on the evaluation method) and barely detected the $\mathrm{II}_{2} \rightarrow \mathrm{II}_{1}$ transition which had nevertheless been easily observed by means of X-rays [7], Raman spectroscopy and thermally stimulated current measurements [1, 6]; its temperature however varied from $\sim 100$ to $117 \mathrm{~K}$ depending on the sample and/or method.

Table I. - Phase transitions in the two phase sequences of crystalline thiophene. The phases are numbered according to the rule proposed in reference [6]. The arrow from II' to III indicates the irreversible recrystallization that may occur from the metastable to the stable sequence.

\begin{tabular}{|c|c|c|c|c|c|c|c|c|}
\hline$T / \mathbf{K}$ & \multicolumn{2}{|c|}{112.35} & 138.5 & \multicolumn{2}{|c|}{170.70} & 175.03 & \multicolumn{2}{|c|}{235.03} \\
\hline $\begin{array}{c}\text { Phase } \\
\text { (stable sequence) }\end{array}$ & V & IV & & & II & & I & Liq. \\
\hline $\begin{array}{c}\text { Phase } \\
\text { (metastable sequence) }\end{array}$ & $\mathrm{II}_{2}$ & $\mathrm{II}_{1}$ & & $I^{\prime}$ & II & & I & Liq. \\
\hline$T / \mathbf{K}$ & \multicolumn{2}{|c|}{90.76} & 139.2 & \multicolumn{2}{|c|}{170.70} & 175.03 & \multicolumn{2}{|c|}{235.02} \\
\hline
\end{tabular}

Disorder (either static or dynamic) was invoked to explain IR data at $100 \mathrm{~K}$ and low frequency Raman broad band widths down to $12 \mathrm{~K}[1,6]$ in both phase sequences. These assumptions were substantiated by NMR results from which Sanford and Boyd [4] conclude that « a fairly rapid molecular motion... " still exists " as low as $85 \mathrm{~K}$ " in the metastable phase sequence. Fried also reached the same conclusion for both sequences at $85 \mathrm{~K}$. It is quite uncommon for such a large molecule to undergo large amplitude reorientations at NMR detectable frequencies at such low temperatures, after three or four solid-solid phase transitions have been crossed on cooling. The quasi-five-fold symmetry of the thiophene molecule led to some speculations, supported by the existence of a multiple-of-five number of equivalent molecular positions at each crystalline site in phases I and III [8], and it was conjectured [1, 2,6] that a glassy crystal or an incommensurate phase would emerge at low temperature.

This conjecture largely motivated the present study of thiophene that was performed between 14 and $300 \mathrm{~K}$ by means of an on-line automated adiabatic calorimeter [9, 10]. A 0.3645 mole thiophene sample was used and its purity was determined to be 99.92 mole \% by gas chromatography. The calorimetric determination gave $99.94 \mathrm{~mole} \%$.

Complete detailed results will be published elsewhere. From now on, we will concentrate on the low temperature results and what can be concluded concerning molecular motions in the different phases.

During the heat capacity measurements in phase $\mathrm{II}_{2}$ at low temperature, an exothermic effect appeared at $\sim 30 \mathrm{~K}$; its intensity increased with temperature and reached a maximum at $\sim 35 \mathrm{~K}$. 
This effect transformed to an endothermic effect around $37 \mathrm{~K}$. The temperature drift went back to normal above $40 \mathrm{~K}$ with the usual few minutes equilibration time. The second series of measurements gave slightly different temperatures for the exothermic peak and for the change from the exothermic to the endothermic effect. These phenomena are characteristic of a glass transition and are explained by a relaxational enthalpy. Figure 1 shows an example of the dependence of the temperature drift rate on temperature and figure 2 shows the heat capacity jump at the glass transition together with the variation of " encraty ", $C_{\mathrm{s}} / T$, as a function of temperature in phase $\mathrm{II}_{2}$. The variation of heat capacity $\Delta C_{\mathrm{s}}$ is $2.04 \mathrm{~J} \mathrm{~K}^{-1} \mathrm{~mol}^{-1}$ at $37 \mathrm{~K}$.

Similar behaviour was observed in phase $\mathrm{V}$ and figure 3 shows the temperature dependence of the spontaneous temperature drifts in this phase. The intensity at the maximum of the exothermic effect was only $1 / 5$ as much as that observed in phase $\mathrm{II}_{2}$ and the magnitude of the heat capacity jump $\Delta C_{\mathrm{s}}$ is $0.60 \mathrm{~J} \mathrm{~K}^{-1} \mathrm{~mol}^{-1}$ at $44 \mathrm{~K}$, that is about $30 \%$ of that observed in phase $\mathrm{II}_{2}$. Figure 4 shows the variation of encraty around the glass transition in phase $\mathrm{V}$.

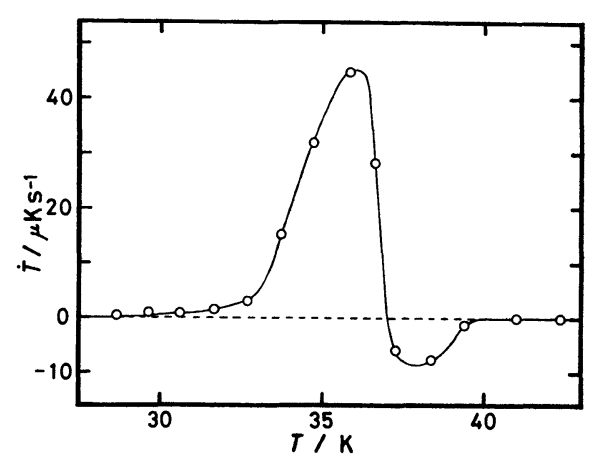

Fig. 1. - Temperature drift rate as a function of temperature near the glass transition in the metastable phase sequence of crystalline thiophene.

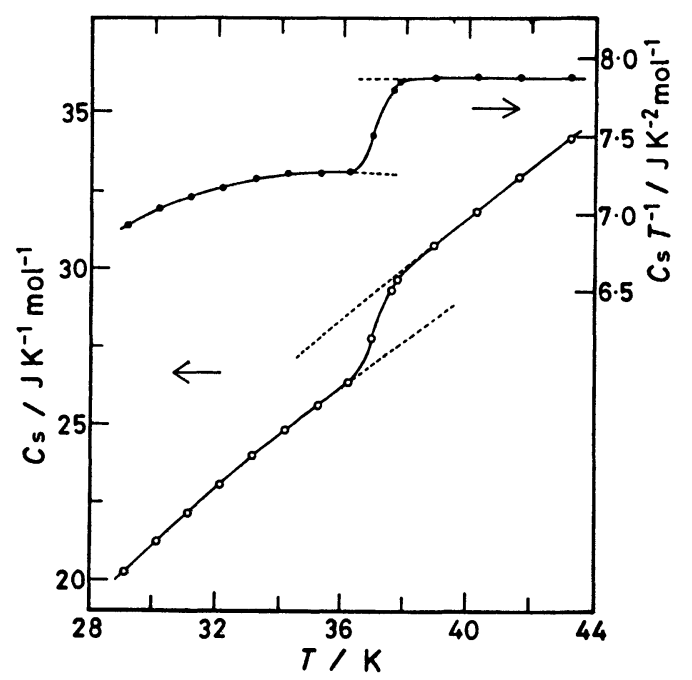

Fig. 2. - Heat capacity, $C_{\mathrm{s}}$, and encraty, $C_{\mathrm{s}} / T$, near the glass transition in the metastable phase sequence of crystalline thiophene. 


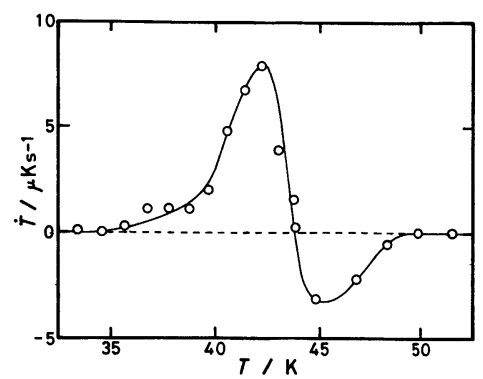

Fig. 3. - Temperature drift rate as a function of temperature near the glass transition in the stable phase sequence of crystalline thiophene.

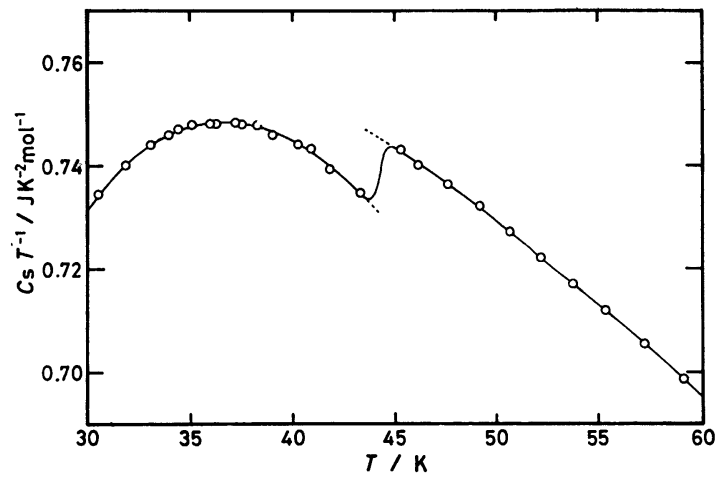

Fig. 4. - Encraty, $C_{\mathrm{s}} / T$, near the glass transition in the stable phase sequence of crystalline thiophene.

The data of exothermic temperature drifts were used for analysing the enthalpy relaxation rate. The estimation of the equilibrium heat capacity was obtained by a simple extrapolation of the heat capacity data above $T_{\mathrm{g}}$ to low temperature. The extrapolation procedure did not significantly affect the final result.

The enthalpy relaxation was supposed to proceed exponentially with a single characteristic time $\tau$ at each starting temperature. The detailed procedure to get $\tau(T)$ has already been described [11].

Afterwards, the activation enthalpy was estimated by assuming that the enthalpy relaxation time follows an Arrhenius law :

$$
\tau=\tau_{0} \exp \left(\frac{\Delta H_{\mathrm{a}}}{R T}\right)
$$

The straight lines of the Arrhenius plots drawn in figures $5 \mathrm{a}$ and $5 \mathrm{~b}$ result from this procedure for phases $\mathrm{II}_{2}$ and $\mathrm{V}$ respectively. The quantities corresponding to the two glass transitions are reported in table II, where the values of $T_{\mathbf{g}}^{\prime}$ have been taken for convenience as the temperatures at which $\tau=10^{3} \mathrm{~s}$. 

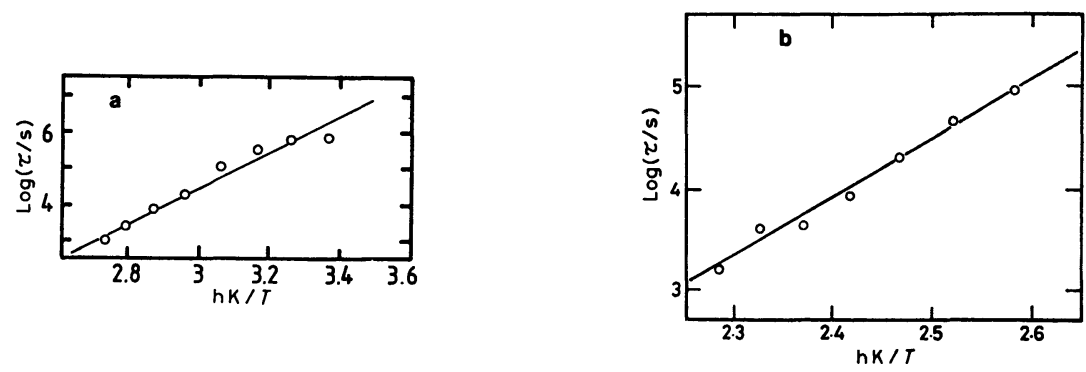

Fig. 5. - Least square fitted Arrhenius plots for the enthalpy relaxation times in the glassy crystalline phases of thiophene : a) metastable sequence; b) stable sequence (the coordinate scales have been chosen so that the slopes of the Arrhenius plots may be directly compared).

It has been assumed for a long time that a glass transition is associated with the freezing of some disorder (reorientational disorder mainly in the case of glassy crystals [12]), and it has been shown recently $[13,14]$ that, for crystalline 1-cyanoadamantane, the glass transition is correlated with the freezing of the sole reorientation of the dipolar axis. So, it has seemed quite natural to relate the glassy state enthalpy relaxation to the slow ordering of the medium and to identify its " microscopic » mechanism to that of the molecular ordering process (see for instance [11]).

In the case of thiophene, the molecular packing of phase I has been studied by Abrahams and Lipscomb [15] and by André et al. [8] who also determined that of phase III. In both phases, herringbone-patterned structures were found. Such structures coud be explained in terms of in-plane reorientations around the molecular quasi-five-fold axis, disregarding a slight fluttering from one side to the other of the mean molecular plane position. As the X-ray diffraction patterns for phases II, $\mathrm{II}_{1}$ and $\mathrm{II}_{2}$ only differ from that of phase I by some superstructure reflexions [7], nothing essential should be changed in the molecular relationships and the herringbone shape should be retained for phase $\mathrm{II}_{2}$. As to the stable phase sequences, the NMR line width exhibits no discontinuities at the III-IV and IV-V transition temperatures [5]; moreover the present work discloses that the heat capacity behaviour is quite similar for the $\mathrm{II}_{-} \mathrm{II}_{1}-\mathrm{II}_{2}$ and III-IV-V phase sequences. We therefore feel it reasonable to assume that the stable phase sequence will also conform to the molecular herringbone pattern and we will retain the uniaxial reorientation

Table II. - Thermodynamic data corresponding to the two glassy crystalline phases of thiophene.

\begin{tabular}{|c|c|c|c|c|}
\hline Phase & $\frac{T_{\mathrm{g}}}{\mathrm{K}}$ & $\frac{\Delta C_{\mathrm{s}}}{\mathrm{J} . \mathrm{K}^{-1} \cdot \mathrm{mol}^{-1}}$ & $\frac{\tau_{0}}{\mathrm{~s}}$ & $\frac{\Delta H_{\mathrm{a}}}{\mathrm{kJ} \cdot \mathrm{mol}^{-1}}$ \\
\hline $\begin{array}{c}\mathrm{V} \\
\text { stable sequence }\end{array}$ & 41.7 & 0.60 at $44 \mathrm{~K}$ & $1.62 \times 10^{-11}$ & $11 \pm 1$ \\
\hline $\begin{array}{c}\mathrm{II}_{2} \\
\text { metastable sequence }\end{array}$ & 36.9 & 2.04 at $37 \mathrm{~K}$ & $4.9 \times 10^{-11}$ & $9.4 \pm 0.9$ \\
\hline
\end{tabular}

$\Delta C_{\mathrm{s}}$ : heat capacity increment at the glass transition; $\tau_{0}$ and $\Delta H_{\mathrm{a}}$ are the parameters characterizing the enthalpy relaxation which is supposed to follow an Arrhenius law $\tau=\tau_{0} \exp \left(\frac{\Delta H_{\mathrm{a}}}{R T}\right) ; T_{\mathrm{g}}$ has been chosen for convenience as the temperature at which $\tau=10^{3} \mathrm{~s}$. 
hypothesis for all phases. This hypothesis agrees with Fried's [5] and Anderson's calculations [16] which show that the value of the NMR line width which is reached in phases III and II' is compatible with a (more-than-2)-fold reorientational motion performed around an axis perpendicular to the molecular plane.

Thus, the apparent activation enthalpy associated with the enthalpy relaxation is to be assigned to this reorientational process.

Other information on the reorientational motions of thiophene molecules may be derived from NMR work. For the stable sequence, broad line NMR measurements show that the second moment, $M_{2}$, drops from the rigid lattice value to a lower one between $\sim 80$ and $\sim 120 \mathrm{~K}$. The inflexion point of the $M_{2}=f(T)$ plot lies at $95-100 \mathrm{~K}$ : it would correspond to a $5.3 \times 10^{-6} \mathrm{~s}$ value for the correlation time $\tau$ of the in-plane reorientational motion [5] (henceforth called " the motion »). From the NMR line width variation as a function of temperature, Fried obtains a coarse estimate of $7 \mathrm{~kJ} \mathrm{~mol}^{-1}$ for the motion within phase $\mathrm{V}$. A more reliable value of $15.5 \mathrm{~kJ} \mathrm{~mol}^{-1}$ in phase I was derived from NMR spin-lattice relaxation time $T_{1}$ measurements by Sandord and Boyd [4].

As to the metastable sequence, a comparison of Fried's and Anderson's [16] NMR broad line data indicates that the inflexion point of the $M_{2}=f(T)$ plot, corresponding to $\tau=5.3 \times$ $10^{-6} \mathrm{~s}$, should lie at 70-80 K. No determination of the activation enthalpy for the motion has been made and we tried to obtain an estimate of it. The $T_{1}=f(T)$ plot exhibits no discontinuity between 130 and $77 \mathrm{~K}$ [16]. Therefore we tentatively assumed that the crossing of the $\mathrm{II}_{1}-\mathrm{II}_{2}$ transition point has no influence on the reorientational process and that a unique Arrhenius law rules the motion from $T_{\mathrm{g}}$ to $130 \mathrm{~K}$. This interpolation leads to a $11.4 \mathrm{~kJ} \mathrm{~mol}^{-1}$ apparent activation enthalpy. The analogous interpolation for the stable sequence gives a value of $12.7 \mathrm{~kJ} \mathrm{~mol}^{-1}$.

The measured relaxation and correlation times are listed in table III as a function of temperature. The corresponding calculated temperatures have been determined by extrapolating the Arrhenius relationships ruling the enthalpy relaxations in both phase sequences. It is clear from table III that the calculated temperatures are systematically too high, which means that the apparent activation enthalpies ruling the enthalpy relaxations are lower than those which rule the motion above the glass transitions. An analogous decrease of the apparent activation enthalpies below $T_{\mathrm{g}}$ had already been observed in the relaxation maps corresponding to crystalline cyclohexanol [17] or to 1-chloro-2-ethyl-hexane [18].

Table III. - Crystalline thiophene : comparison between the experimental correlation times (as derived from NMR data) and the extrapolated relaxation times starting from the Arrhenius relationships ruling the enthalpy relaxations as characterized in table II.

\begin{tabular}{|c|c|c|c|c|c|c|}
\hline$\tau / s$ & & & $10^{3}$ & $5.3 \times 10^{-6}$ & $5.16 \times 10^{-9}$ & $2.65 \times 10^{-9}$ \\
\hline \multirow{2}{*}{$\begin{array}{c}\text { Stable } \\
\text { sequence }\end{array}$} & \multirow{2}{*}{$\frac{T}{\mathrm{~K}}$} & experimental & 41.7 & $95-100[5]$ & $145[4]$ & \\
\hline & & calculated & & $104 \pm 10$ & $229 \pm 21$ & \\
\hline \multirow{2}{*}{$\begin{array}{c}\text { Metastable } \\
\text { sequence }\end{array}$} & \multirow{2}{*}{$\frac{T}{\mathrm{~K}}$} & experimental & 36.9 & $70-80[5,16]$ & & $130[18]$ \\
\hline & & calculated & & $97 \pm 9$ & & $283 \pm 27$ \\
\hline
\end{tabular}

$\tau=5.3 \times 10^{6} \mathrm{~s}$ corresponds to the inflexion point of the plot of the NMR second moment as a function of $T$ [5]; the values $\tau=5.16 \times 10^{-9} \mathrm{~s}$ and $2.65 \times 10^{-9} \mathrm{~s}$ correspond to the correlation times at the minima of the plots $T_{1}=f\left(\frac{1}{T}\right)$ for the stable [4] and metastable [16] phase sequences, respectively. 
The activation enthalpies ruling the enthalpy relaxation and the motion within both phase sequences are respectively of the same orders of magnitude. This substantiates the assumption that both processes are related.

As the temperature is decreased, ordering processes of orientational disorder initially existing in phase I will proceed in both phase sequences. Modifications (if any) of these processes will occur discontinuously at the respective phase transitions, and the remaining disorder is believed to freeze before the completely ordered state is reached, as in the cases of stannous chloride dihydrate [11] and orthoboric acid crystals [19].

In the present case, a glass transition occurs in each phase sequence; it is tempting to relate it to the quasi-five-fold symmetry of the thiophene molecule; it points towards some self-limiting structure (see for instance [20]) which could be considered as the origin of disorder. Glass-like transitions have already been observed in solids of similar five-membered heterocyclic molecules (thiazole [21], isoxazole [22]). There must be a common physical basis in all these freezing phenomena.

\section{References}

[1] Figuière, P., Thèse, Orsay, N.O. 2538 (1981).

[2] André, D., Dworkin, A., Figuière, P., Fuchs, A. H. and Szwarc, H., C.R. Hebd. Séan. Acad. Sci. Paris, Ser. II 295 (1982) 145.

[3] Waddington, G., Knowlton, J. W., Scott, D. W., Oliver, G. D., Todd, S. S., Hubbard, W. N., Smith, J. C. and Huffman, H. M., J. Am. Chem. Soc. 71 (1949) 797.

[4] Sanford, W. E. and Boyd, R. K., Can. J. Chem. 54 (1976) 2773.

[5] FrIED, F., Thèse, Nice, A.O. CNRS no 9740 (1974).

[6] André, D., Dworkin, A., Figuière, P., Fuchs, A. H. and Szwarc, H., Phys. Chem. Solids, in press.

[7] ANDRÉ, D. and Szwarc, H., unpublished results.

[8] André, D., Figuière, P., Fourme, R., Ghelfenstein, M., Labarre, D. and Szwarc, H., J. Phys. Chem. Solids 45 (1984) 299.

[9] Sugisaki, M., Suga, H. and SeKi, S., Bull. Chem. Soc. Jpn 38 (1965) 1000.

[10] Kishimoto, K., Suga, H. and SeKi, S., Bull. Chem. Soc. Jpn 53 (1980) 2748.

[11] Matsuo, T., Oguni, M., Suga, H., Seki, S. and Nagle, J. F., Bull. Chem. Soc. Jpn 47 (1974) 57.

[12] Adachi, K., Suga, H. and SeKI, S., Bull. Chem. Soc. Jpn 41 (1968) 1073.

[13] Fuchs, A. H., Thèse, Orsay, N.O. 2802 (1983).

[14] Peneau, A., Fuchs, A. H., Guibe, L. and Szwarc, H., C.R. Hebd. Séan. Acad. Sci. Paris, Ser. II 298 (1984) 551.

[15] Abrahams, S. C. and Lipscomb, W. N., Acta Crystall. 5 (1952) 93.

[16] Anderson, J. E., Mol. Cryst. Liq. Cryst. 11 (1970) 343.

[17] Adachi, K., Suga, H., Seki, S., Kubota, S., Yamaguchi, S., Yano, O. and Wada, Y., Mol. Cryst. Liq. Cryst. 18 (1972) 345.

[18] Heitz, R. J. and SzwarC, H., Revue Phys. Appl. 15 (1980) 687.

[19] Oguni, M., Matsuo, T., Suga, H. and Seki, S., Bull. Chem. Soc. Jpn 50 (1977) 825.

[20] Hoare, M., in " The glass transition and the nature of the glassy state ", Eds. M. Goldstein and R. Simha, Ann. New York Acad. Sci. 279 (1976) 186.

[21] Goursot, P. and Westrum, E. F. Jr., J. Chem. Eng. Data 13 (1968) 471.

[22] Bessada, C., Dworkin, A., Szwarc, H. and Vassal, A., unpublished results. 